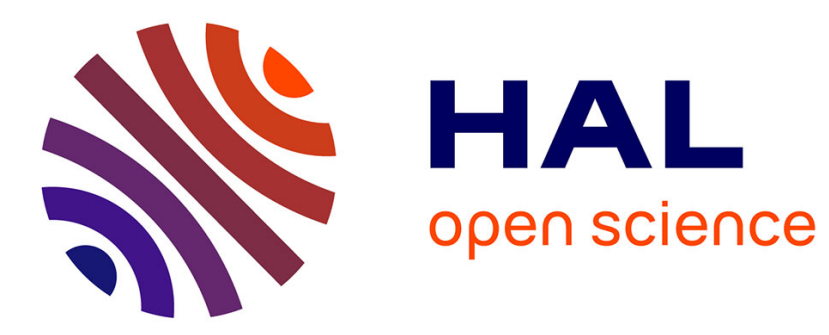

\title{
To what extent can micro-and macroplastics be trapped in sedimentary particles? A case study investigating dredged sediments
}

Mel Constant, Claire Alary, Isabelle de Waele, David Dumoulin, Noémie Breton, Gabriel Billon

\section{To cite this version:}

Mel Constant, Claire Alary, Isabelle de Waele, David Dumoulin, Noémie Breton, et al.. To what extent can micro-and macroplastics be trapped in sedimentary particles? A case study investigating dredged sediments. Environmental Science \& technology, 2021. hal-03219290

\section{HAL Id: hal-03219290 \\ https://hal.science/hal-03219290}

Submitted on 6 May 2021

HAL is a multi-disciplinary open access archive for the deposit and dissemination of scientific research documents, whether they are published or not. The documents may come from teaching and research institutions in France or abroad, or from public or private research centers.
L'archive ouverte pluridisciplinaire HAL, est destinée au dépôt et à la diffusion de documents scientifiques de niveau recherche, publiés ou non, émanant des établissements d'enseignement et de recherche français ou étrangers, des laboratoires publics ou privés. 


\section{To what extent can micro- and macroplastics be}

2 trapped in sedimentary particles? A case study

3 investigating dredged sediments.

4 Mel Constant $^{t^{* *}}$, Claire Alary ${ }^{\dagger}$, Isabelle De Waele ${ }^{*}$, David Dumoulin ${ }^{*}$, Noémie Breton ${ }^{*}$ and

5 Gabriel Billon

6 †Univ. Lille, Institut Mines-Télécom, Univ. Artois, Junia, ULR 4515 - LGCgE, Laboratoire

7 de Génie Civil et géo-Environnement, F-59000 Lille, France

8 Univ. Lille, CNRS, UMR 8516 - LASIRE, Laboratoire Avancé de Spectroscopie pour les

9 Interactions, la Réactivité et l'Environnement F-59000 Lille, France

10 Keywords: macroplastics, microplastics, dredging sediment, FTIR. 
Plastic wastes and their fragments (microplastics, MPs $<5 \mathrm{~mm}$ ) represent a global, persistent, and ubiquitous threat to ecosystems. Their sources, transfers and fates are still poorly understood, especially in rivers. To fill this gap, sediments were collected from two dredging disposal sites along the Aa River (France). Four pits were dug, and triplicate samples were obtained at four depths (down to $140 \mathrm{~cm}$ ). The sediments were sieved to $5 \mathrm{~mm}$ to collect macroplastics (MaPs). MPs were separated from the sediment based on density using a NaI solution $(1.6 \mathrm{~g} / \mathrm{mL})$. Suspected plastics were analyzed with Fourier Transform InfraRed (FTIR) spectroscopy. The studied sediments were found to be widely contaminated with concentrations ranging from 0.97 to $77 \mathrm{MaPs} / \mathrm{kg}$ and from 0.78 to $2800 \mathrm{MPs} / \mathrm{kg}$, which were one to four orders of magnitude lower than those in most polluted European riverbeds. The MaPs were principally PE, PP, PS and PVC films, whereas the MPs were mainly PA and PES fibers. The plastic concentrations and features of the two sites, which were filled at two different times, differed. Several factors occurring before and after dredging operations may explain these discrepancies. Nevertheless, no relationships with the sediment features were noted, and thus, one major driving force could not be identified. At the site scale, more than 1 ton of plastic could be stored. In conclusion, this study highlights the importance of dredged sediments for past plastic pollution studies and global plastic budget estimations. 


\section{Introduction}

Anthropogenic litter, notably plastic pollution, is one of the most visible, ubiquitous and durable threats to terrestrial ecosystems ${ }^{1,2}$. Plastics can enter a broad range of animal bodies, including humans, through ingestion, breathing or trophic transfer ${ }^{3-5}$ and are frequently associated with an extensive range of chemical substances ${ }^{6-8}$. This is particularly true for small pieces of plastic, commonly called microplastics (MPs $<5 \mathrm{~mm})^{9}$. These hazards are reinforced by the slow degradation of plastic, especially in environments with low UV radiation, temperature and oxygen, such as the deep sea and sediments ${ }^{10}$.

Data on plastic debris distributions in terrestrial environments are sparse compared with those in marine environments ${ }^{11}$. However, considerable amounts of anthropogenic litter sink in or transit through freshwater systems ${ }^{12}$. A limited number of studies have been conducted on plastic deposited in riverbeds ${ }^{13}$. Notably, to our knowledge, only one investigation has been conducted on MPs trapped in dredged sediment ${ }^{14}$. These materials can provide qualitative and quantitative information on past pollution. Because long-term monitoring is lacking, studying sediment records is notably interesting for unraveling the dynamic accumulation of MPs. In particular, dredged sediment may provide a snapshot of the pollution at a certain moment in time, because sediment removal stops hydrologic processes. This information is necessary for understanding the settlement of plastics, improving global budgets and predicting forthcoming trends. In addition, terrestrial deposit sites are often easier to sample than bed sediment. The challenging objectives of our study were to examine the quantitative (i.e., density) and qualitative (i.e., size, shape and polymer composition) distributions and properties of MaPs and MPs within sediments deposited during two periods. Our investigations provide relevant results concerning the knowledge of past plastic contamination in dredged sediments and open the way for further investigations in the near future. 
57 Sediments were sampled in May 2019 at two sites in a dredging disposal area (Figures 1A, B and C). The sites (Site 1: 2004; Site 2: 2016) were filled with dredged materials from the Aa River, a North Sea coastal river with a small sparsely populated and industrialized drainage catchment $\operatorname{area}^{15,16}$ (see Supporting Information (SI) for further details). At the first 61 site, three pits $(1.5 \times 1.5 \mathrm{~m})$ were dug $30 \mathrm{~m}$ apart to a depth of $1.5 \mathrm{~m}$ (Figure 1D). Overall, the sediments were coarse but with considerable horizontal (between pits) and vertical (between depths) heterogeneities (SI Table S1 and Figure S3). At the second site, only one pit $(1.5 \times$

$641.5 \times 1.5 \mathrm{~m})$ was dug, and the sediments were fine and homogeneous. The sediments were 65 collected with a metal trowel at four depths $(0-10,20-30,80-90$ and 130-140 cm; see SI for 66 details). 

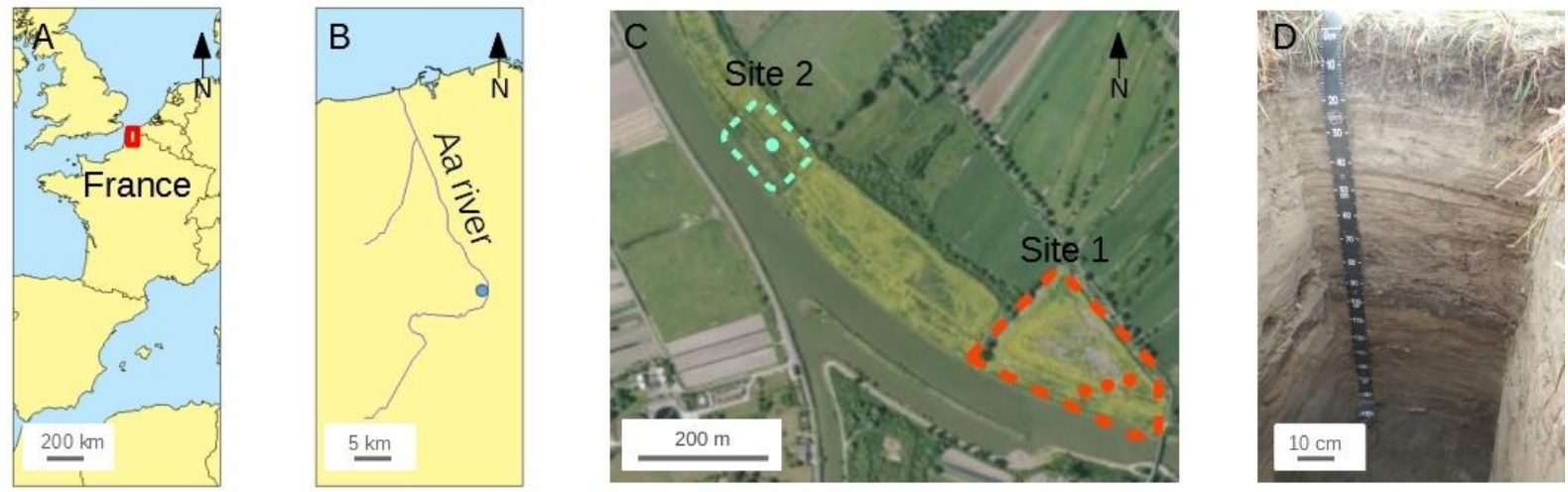

68 Figure 1. Location maps and pictures of the study area. A) General map of France. Red

69 rectangle shows the Aa River location. B) Sampling site (circle) along the Aa River Basin. C)

70 Aerial pictures of the sampling sites. Dashed polygons show the borders of each site, and circles indicate the positions of the pits. D) Picture of a pit at site 1. 


\section{Preparation of the samples prior to analysis}

MaPs were extracted using a $5 \mathrm{~mm}$ metal sieve (see SI for details). After removing most of the organic matter with $\mathrm{H}_{2} \mathrm{O}_{2}(3 \%)$, the MPs were separated from the sediment using NaI (1.6 $\mathrm{g} / \mathrm{mL}$ ) density-based extraction according to Claessens et al. ${ }^{17}$, which was adapted to our samples (see SI for details). Finally, the plastics were observed, photographed, measured and sorted into five shape categories using a dissecting stereomicroscope (SI Figures S1 and S2).

\section{FTIR spectroscopy and granulometric analysis}

A total of 62 suspected MaPs (13\% of the sorted particles) and 166 suspected MPs (14\%) were analyzed by Fourier Transform InfraRed (FTIR) spectroscopy to determine whether they were actually plastics and, in this case, to determine their polymeric composition (see SI for details). Large particles $(>500 \mu \mathrm{m})$ were analyzed by FTIR-ATR spectroscopy, whereas fibers, due to their small volumes, and other small particles (between 500 and $150 \mu \mathrm{m}$ ) were analyzed by micro-FTIR spectroscopy.

The sediment particle size distribution (between 0.04 and $1000 \mu \mathrm{m}$ ) was determined for each sample following standardized laser diffraction methods (see SI for details).

\section{Data analysis}

FTIR analysis and contamination controls were used to correct the initial sorting and accurately identify true MaPs and MPs in our samples. First, the abundances of fibers in the controls (the only shape observed) were subtracted from the initial count. Blank-corrections represented less than 5\% of the MP initial counts. Then, for each shape category, an identified plastic ratio was accordingly applied. This ratio was calculated by dividing the number of particles confirmed to be plastic by FTIR analysis by the total number of items analyzed and visually described as "potential plastics". All the MaP and MP contents and the relative contents of the shapes given in the following text, figures and tables are based on the FTIRand blank-corrected results. Ultimately, the concentrations of MaPs and MPs were estimated 
97 by dividing the corrected numbers and mass of plastic items by the weight of the dry sediment 98 processed (items and $\mathrm{mg} / \mathrm{kg}$; for statistical analysis details, see $\mathrm{SI}$ ). 
Results

\section{Plastic quantities}

101 Both macroplastics (MaPs) and microplastics (MPs) were detected in all the sediment samples. The concentrations were widely distributed over three to five orders of magnitude

103 (SI Table S2). The MaP concentration ranged from 0.93 to 77 items $/ \mathrm{kg}$ and from 11 to 760 $104 \mathrm{mg} / \mathrm{kg}$. The MP concentration varied between 0.78 and 2,800 items $/ \mathrm{kg}$ and between 0.38 and $105240 \mathrm{mg} / \mathrm{kg}$.

106 The concentrations, except the MaP numerical concentrations, at the two sites were 107 significantly different (Wilcoxon test; Figures 2A and D and SI Table S3). At site 1, no 108 significant differences were observed in the MP concentrations of concomitant samples 109 collected $30 \mathrm{~m}$ apart (SHR test; Figures 2B and E). However, the MaP numerical 110 concentrations at the pits were significantly different (SHR test; Figures $2 \mathrm{~B}$ and E). The 111 vertical patterns of the MPs and MaPs were relatively similar at site 1 , but not at site 2

112 (Figures 2C and F). At both sites, however, the concentrations at the different depths were not 113 significantly different, except MP numerical concentrations (Kruskal-Wallis and SHR tests). 

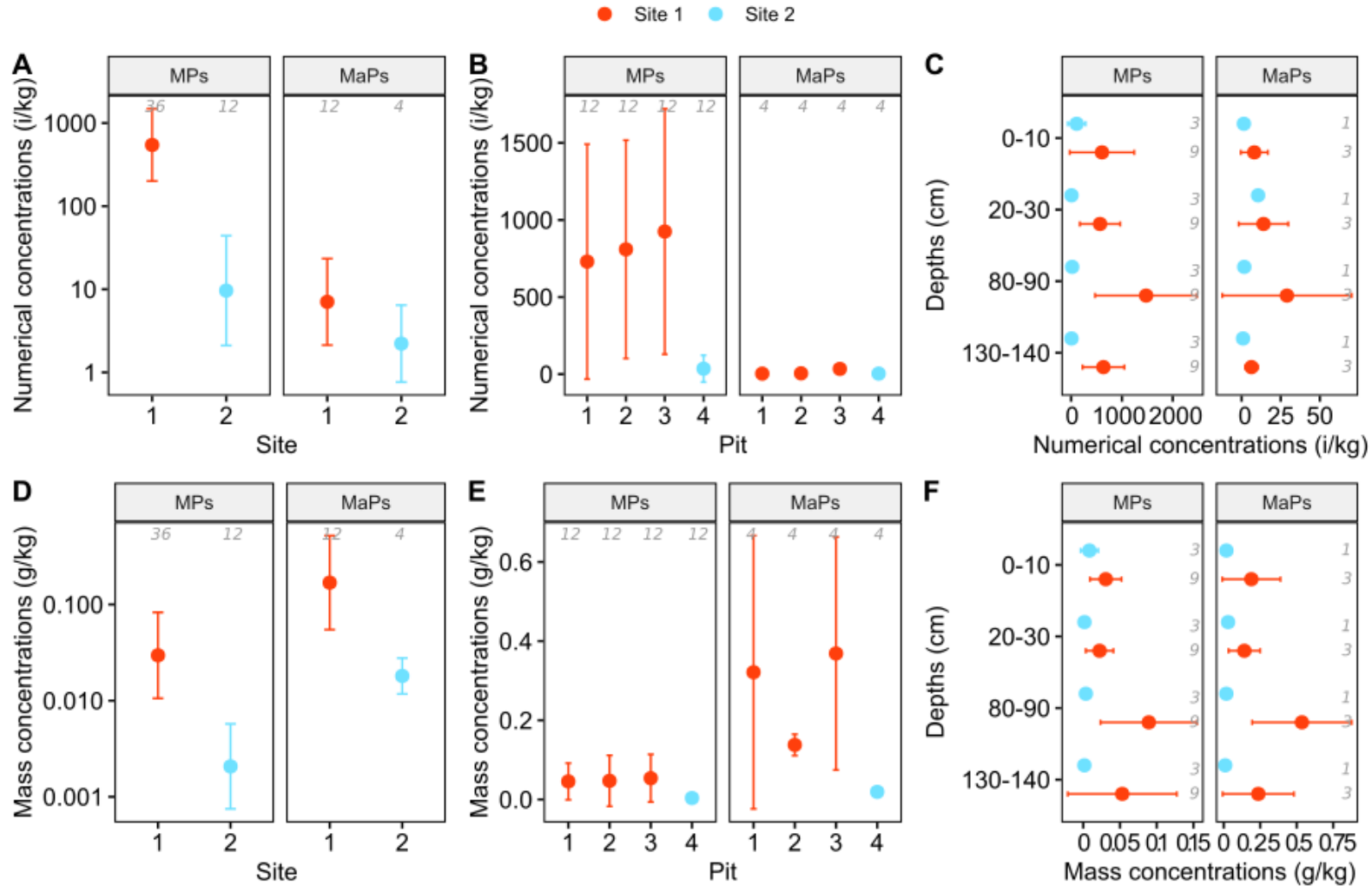

Figure 2. Mean plastic concentrations per $\mathrm{kg}$ of dry sediment (item $/ \mathrm{kg}$ and $\mathrm{g} / \mathrm{kg}$ ). A, D)

Concentrations at both sites expressed in items/kg (A) and $\mathrm{g} / \mathrm{kg}$ (D) (the horizontal axis is

117 scaled by a logarithm base 10 transformation). B, E) Concentrations in each pit at both sites

118 expressed in items $/ \mathrm{kg}$ (B) and $\mathrm{g} / \mathrm{kg}(\mathrm{E})$. C, F) Concentrations at each depth for both sites

119 expressed in items $/ \mathrm{kg}(\mathrm{C})$ and $\mathrm{g} / \mathrm{kg}(\mathrm{F})$. The bars represent the standard deviation from the mean. The gray italic numbers indicate the number of samples. 
122 No relationship was observed between the concentration of plastics and the sediment 123 features, such as the percentages of sediment smaller than 2 (clay), 20 (silt) and $200 \mu \mathrm{m}$ 124 (sand) or the particle size corresponding to $10 \%, 25 \%$, and $50 \%$ of the accumulated volume of 125 sediment (see, for instance, Figure 3). At site 1, the numerical and mass concentrations 126 covaried significantly for both the MPs and MaPs (Pearson test; SI Figure S5A). Similarly, 127 the masses of the MPs (average per sample) and MaPs exhibited a positive and significant 128 linear relationship, in contrast to the numerical concentrations (Pearson test; SI Figure S5B). 129 When the concentrations at site 2 were added to the data set, the p-values of the linear 130 regressions were slightly improved, but the overall results remained similar (Pearson test). 
Site $1 \rightarrow$ Site 2
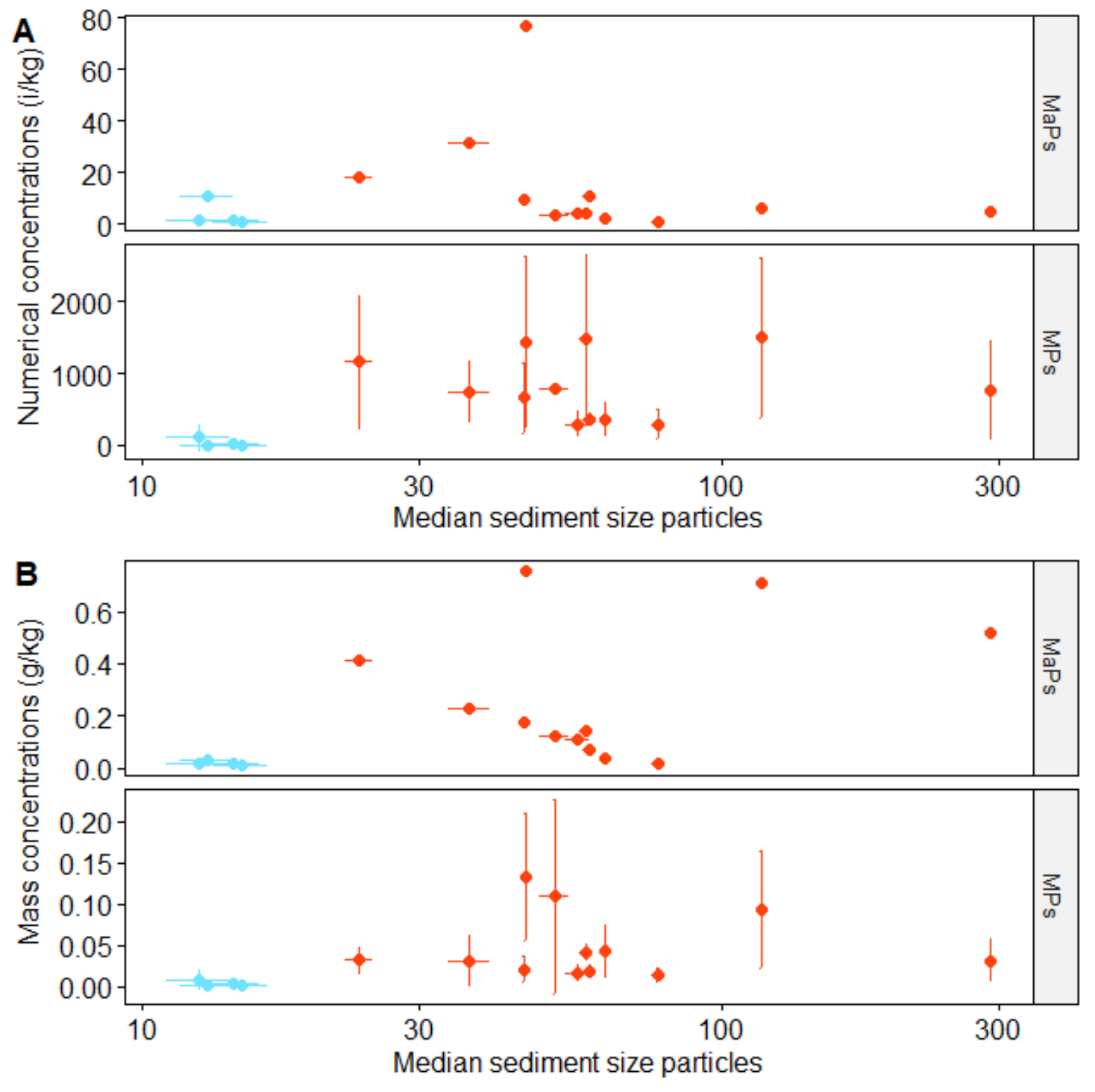

132 Figure 3. Relationships between the plastic concentrations and sediment features. Numerical

133 (A) and mass (B) concentrations are plotted as functions of the median sediment grain sizes of 134 the macroplastics (MaPs) and microplastics (MPs). The concentrations are expressed in 135 items $/ \mathrm{kg}$ (A) and $\mathrm{g} / \mathrm{kg}$ (B). The horizontal axis is scaled by a logarithm base 10 136 transformation. 
138 Due to the large number of shape categories considered (SI Figures S1 and S2), data from 139 independent samples were pooled within each study site. A similar distribution was observed 140 at both sites, but the distributions of the MaPs and MPs were different. For the MaP size class, 141 films were the most abundant shape found at site $1(90 \%$; Figure 4$)$ and the only shape 142 observed at site 2. Fragments were the second most abundant shape by number (9\%) at site 1. 143 The amounts of foams and microbeads were negligible $(<1 \%)$ at both sites. No MaP fibers 144 were observed at either site.

145 For the MP size class, fibers were the most abundant shape found at both sites (Site 1: 65\%; 146 Site 2: 86\%), followed by fragments (Site 1: 20\%; Site 2: 11\%) and films (Site 1: 11\%; Site 2: 147 4\%; Figure 4). Microbeads were less common $(<5 \%)$ at site 1 and not found at site 2. No MP 148 foam was observed at either site. 


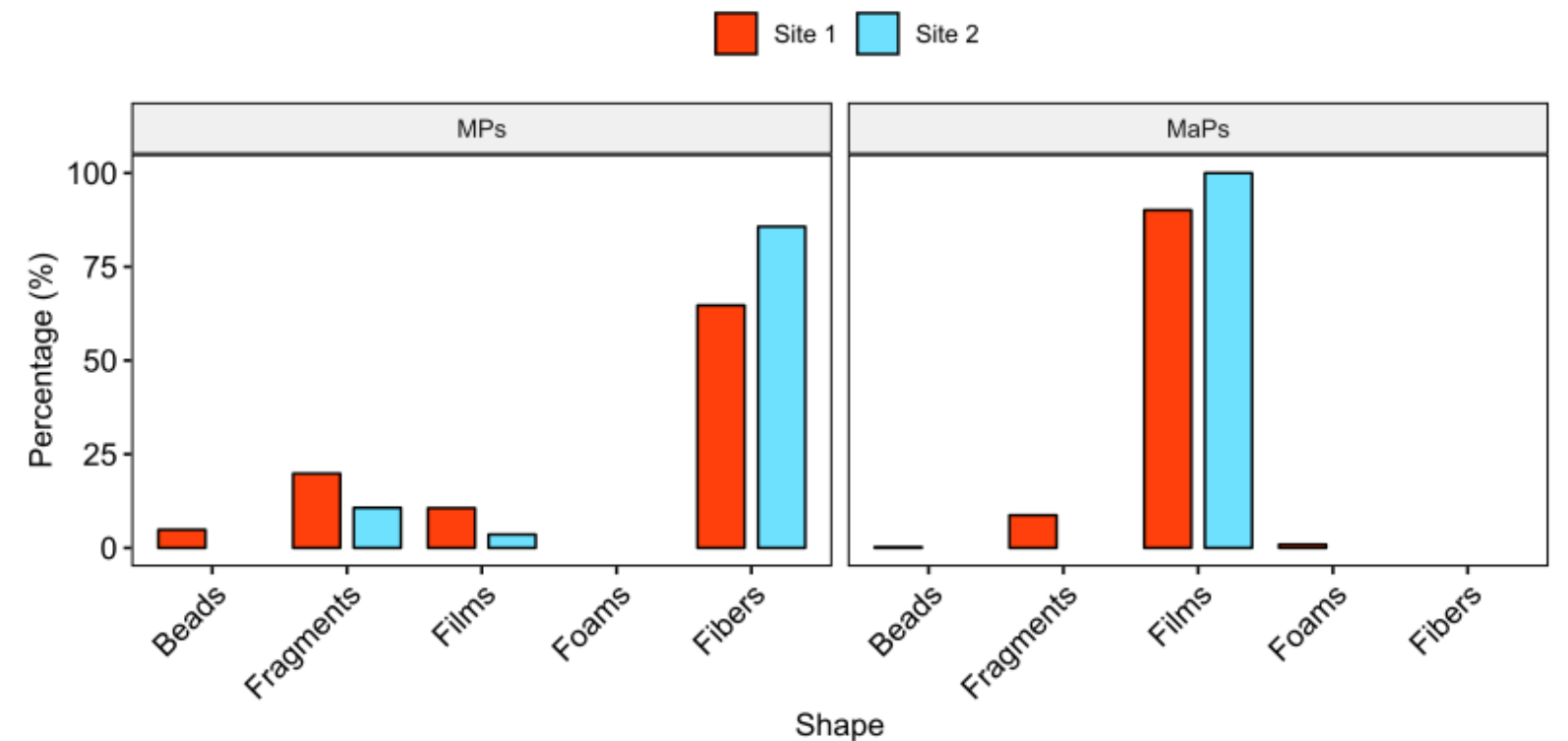

149

150 Figure 4. Shape distributions of the microplastics (MPs) and macroplastics (MaPs) found at 151 both sites. 


\section{Polymer composition}

153 Twenty different polymer types were identified from all the sediment samples. Only a 154 limited number of suspected MaPs were not synthetic polymers (2/60 particles identified by

155

156

157 FTIR spectroscopy; 60/62 particles were identified) but wood or cellulose (SI Figure S4). Therefore, the rate of correctly identified plastics was high $(97 \%)$ for large particles. However, the results obtained by FTIR spectroscopy confirmed the necessity of performing plastic polymer analysis on small plastics, particularly fibers, for correcting the data. Indeed, we found that less than half (9/26 particles identified) of the binocular-sorted MP fibers were actually plastic. This low percentage $(35 \%)$ of plastic is likely related to the difficulty in discriminating between plastic fibers and cotton and plant fibers with binoculars or a dissecting stereomicroscope. For the plastic fibers, polyamide (PA), polyester (PES) and polyvinyl chloride (PVC) were the three most abundant polymers (33, 22 and 11\%, respectively; Figure 5). In contrast, the identification of other plastic shapes (films, fragments, foams and beads) was mostly successful (114/134 or 85\%; 134/140 particles were identified). For those shapes, the polymers were mainly the same for both plastic size classes (Figure 4). The MaPs were principally made of PVC (31\%), polyethylene (PE; 24\%), polypropylene (PP; $21 \%$ ) and polystyrene (PS; 21\%), and the MPs (other than the fibers) were mainly composed of PE (33\%) and PVC (24\%). 


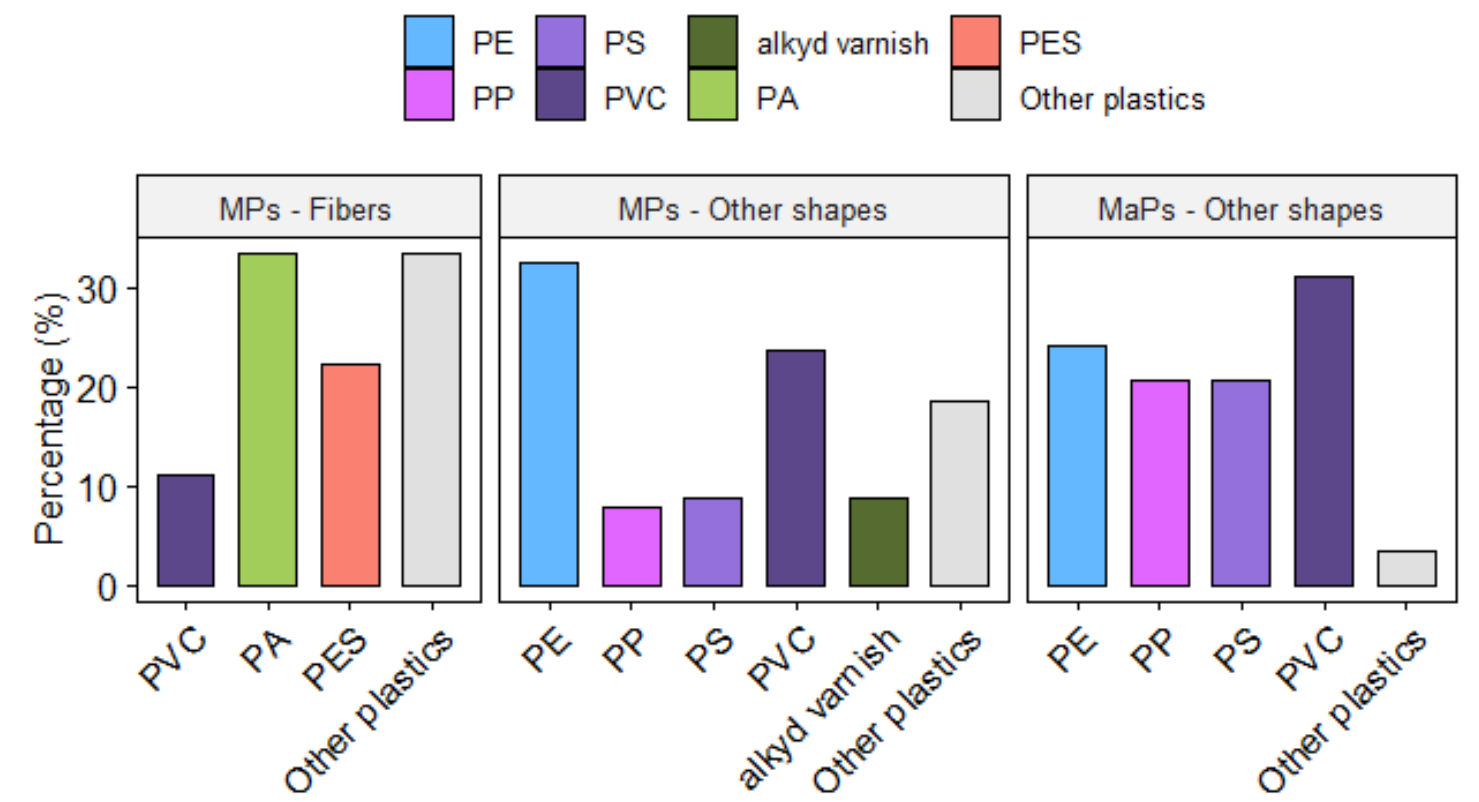

171 Figure 5. Synthetic organic polymer compositions of the MaPs and MPs found at both sites.

172 Shapes: fibers and other shapes (fragments, foams, films and beads). Polymers: polyethylene

173 (PE), polypropylene (PP), polystyrene (PS), polyvinyl chloride (PVC), alkyd varnish, 174 polyamide (PA), polyester (PES), other plastics (e.g., polyethylene terephthalate, 175 polyurethane, polyacrylamide), as determined by FTIR spectroscopy analysis. See details in 176 the FTIR spectroscopy section for polymer identification and SI Figure S4 for the percentages 177 of plastic, unidentified and non-plastic sorted particles. 
179 After all the sorted particles were measured, no marked differences were observed between 180 the MaP and MP size distributions of the two sites (Figure 6). The MaPs ranged from 5 to 230 $181 \mathrm{~mm}$, and the MPs ranged from 167 to $4939 \mu \mathrm{m}$. The MaPs exhibited a unimodal distribution 182 skewed towards smaller size classes, and the medians were approximately 20 (site 1) and 24 $183 \mathrm{~mm}$ (site 2). The MP size distribution, which had a median of approximately $1 \mathrm{~mm}$, was 184 similar to the MaP size distribution at site 1. At site 2, the MPs exhibited a rather stochastic 185 distribution. Only a few particles were observed in the size classes near the sieve meshes 186 (MaPs: $5 \mathrm{~mm}$; MPs: $125 \mu \mathrm{m}$ ), probably because the size was measured based on the longest 187 dimension. These particles could pass through the sieve by their narrowest dimensions and 188 were therefore not collected and counted. 

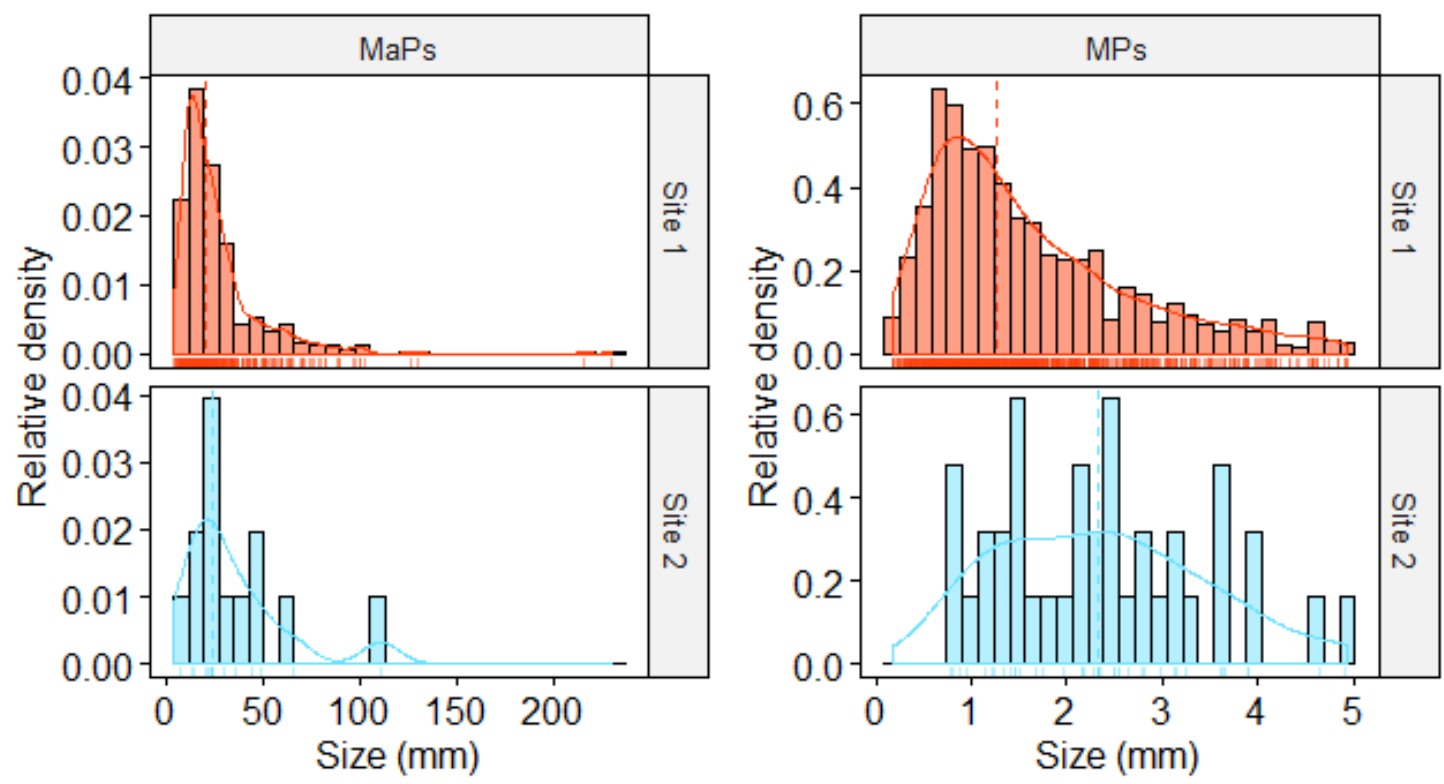

190 Figure 6. Relative densities of the macroplastics (MaPs) and microplastics (MPs) within each

191 size class at each site. Size: longest dimension of the items. Density: number of plastics 192 within a size class, scaled to 1 . Width of the size class bars: $8 \mathrm{~mm}$ (MaPs) and $0.17 \mathrm{~mm}$ 193 (MPs). The lines show the density curves, and the dashed lines indicate the median values. 


\section{Discussion}

\section{Plastic pollution in the Aa River}

In dredged sediments, buried plastics could indicate the average levels of the past plastic pollution of riverbed sediments. At the two studied sites, sediments were deposited at an approximate interval of a decade. The plastic quantities were more substantial at site 1 (deposit date: 2004) than at the more recent site 2 (deposit date: 2016). Dissimilarities in the shape partitions were also observed, whereas differences of the polymer and size distributions were limited. The plastic quantities and features could change both before and after deposition through distinct processes. Before dredging operations, sediments and their pollutants are predominantly affected by river inputs, flow variations, sedimentation rates, resuspension events, etc. After the deposition of dredged sediments, the sediments evolve into new soil with the development of pioneer vegetation, as observed at our study site, and other mechanisms can occur (e.g., slow reoxidation processes, infiltration, bioturbation, bioabsorption, etc.).

Before sediments are transferred to dredging deposition sites, they accumulate plastics that sediment into the riverbed. On the one hand, the deposition of plastics in riverbeds depends on the pool of plastics released to the environment, which is related to the local uses of plastics and waste management. Plastic production and consumption have increased since the middle of the twentieth century ${ }^{9}$. In developed countries, waste management has concurrently improved over the last decade. On the other hand, similar to the deposition rate of other suspended matter ${ }^{18}$, the plastic deposition rate may have changed due to a hydrodynamic change (i.e., course of the river and/or river flow velocity $)^{18}$. Accordingly, the dissimilarity of the sites in terms of both the sediment features and plastics may be related. Nevertheless, the mechanisms that govern the settling process of plastics into bed sediments are imperfectly 
known. Moreover, the distribution of plastic debris is highly heterogeneous, even at a scale as 219 small as a few meters ${ }^{19-22}$.

220 After dredging operations, the evolution of synthetic polymers over time within deposited 221 sediments, similar to soils, remains largely unknown ${ }^{23}$. In our case, the development of 222 pioneer vegetation is accompanied by other processes (e.g., slow reoxidation processes, 223 rainwater infiltration, bioturbation, bioabsorption). Therefore, the dredged sediments do not necessarily reflect the initial contamination state of the river. The conditions of the subsurface are rather stable, with moderate temperatures and no UV radiation, which is unfavorable for degradation ${ }^{10}$. Nevertheless, the initial quality and quantity of plastic may change, at least due to biodegradation ${ }^{24}$. In addition, initial plastic distributions can also change if particles migrate through infiltration and bioturbation ${ }^{25-27}$. The dredging processes in channeled rivers also result in an important perturbation and resuspension of settled particles. An unknown fraction of resuspended particles, including plastics, may finally migrate downstream in the river, reducing the total amount of plastic particles transferred to the deposition site. At both sites, light plastic polymers were observed in non-negligible quantities (Figure 5). Among them, PE, PP and PS were logically the most abundant. They were among the most produced polymers during the last decade ${ }^{28}$. However, they have a density below or slightly higher than $1 \mathrm{~g} / \mathrm{cm}^{3}$ and should float in freshwater systems. Physical and biological processes can force buoyant plastics to $\operatorname{sink}^{29}$, but the observations needed to estimate their occurrences are lacking. In addition, after this extended period of storage, the most breakable plastics may have been fragmented through degradation, becoming smaller than our detection size limit.

239 Films were predominant in the MaPs, whereas they constituted a negligible fraction of the MPs (Figure 4). Similar to the ratio of polymers, a rather similar shape ratio could be expected along the plastic size range, from the longest MaPs to the smallest MPs, with the exception of fibers, which are primarily micrometric in size and consequently absent from the 
$243 \mathrm{MaPs}^{30}$. These dissimilar patterns can indicate differences in the fragmentation rates of the 244 shapes or in the sources. Plastic films are used in packaging or bags, which are short-life 245 objects released into the environment in micrometric sizes. Indeed, they are among the most 246 frequent MaPs found at river surfaces ${ }^{31}$. Fragments may be more prone to surface layer 247 fragmentation, resulting in the release of smaller pieces that are not detectable by our 248 procedure.

249 The size distribution at site 1, especially that of the MPs, was subtly shifted towards the smallest dimension compared with that at site 2, a pattern, which could indicate stronger degradation and is consistent with the historical context of the samples. Nonetheless, many other factors may affect the size distribution, including shape and polymer discrepancies.

By multiplying the median concentrations of the plastics (SI Table S2) by the volume of the sediment, we could roughly estimate that $3 \times 10^{10}$ items $(>125 \mu \mathrm{m})$ or 9 tons of plastics are trapped within site $1\left(3.8 \times 10^{4} \mathrm{~m}^{3}\right)$ and $5 \times 10^{8}$ items or 0.9 tons are trapped in site $2(1.5 \times$ $10^{4} \mathrm{~m}^{3}$ ). In France, more than $1.4 \times 10^{6} \mathrm{~m}^{3}$ of riverbed sediments are dredged every year ${ }^{32}$. Plastic budget estimations do not currently incorporate those sections. Deposit sites constitute ultimate plastic sinks, which, unlike riverbeds, are unaffected by flooding and, if not perturbed by human activities, will persist. Once deposited, dredged sediments evolve into new soil, and the presence of plastics may have a significant and durable impact on soil ecosystem development ${ }^{33}$.

\section{External forcing of the plastic distribution within dredged sediments}

As indicated above, plastics trapped in dredged sediments are not directly comparable to their counterparts settled in riverbeds. Within watersheds, plastic distributions depend on various factors, such as hydrology and human activities ${ }^{34}$. When dredged sediments are deposited at storage sites, this initial distribution is probably perturbed. First, sediments are taken out of the river and put in an intermediate container (e.g., boats or trucks), which tends 
to homogenize the grain size distribution and may result in the incorporation of new plastics from the container (i.e., contamination). Then, the sediments are deposited at storage sites using pumps, which creates horizontal and vertical granulometric gradients. In fact, because large grains settle more rapidly, the size of the sediments gradually decreases from the pump to the opposite corner of the site and from the bottom to the surface.

Because the data at site 2 are limited, only the variability at site 1 is discussed. At this site, 3 pits were dug $30 \mathrm{~m}$ apart. They were deposited during the same operation and came from the same river localization. Due to the filling process, the grain size at site 1 gradually decreased from pit 1 to pit 3 (south to north; Figure 1 and SI Figure S3). No covariations between the plastic concentrations and grain size distributions were observed (Figure 3). Plastics and sediments may behave and settle differently because of differences in the shape, size and density distributions ${ }^{35}$. More precisely, sediment shapes range from nearly spherical (e.g., mature siliciclastic sediment) to nearly flat (e.g., muscovite, biotite), MaPs are mostly films ( 2D shape), and MPs are mainly fibers (elongated and thin cylinders). The medians of the sediment sizes ranged from 10 to $100 \mu \mathrm{m}$, the MaP median was approximately 20-24 mm, and the MP median was $1 \mathrm{~mm}$. Finally, the volumetric mass density of the sediments was greater than $2 \mathrm{~g} / \mathrm{cm}^{3}$, and the densest polymers observed (PVC and PET) had a density of 1.4 $\mathrm{g} / \mathrm{cm}^{3}$.

Even if the plastics and sediments features are different, the plastic distribution could still follow the same gradient as the sediments, with larger, denser, more spherical and less weathered plastics settling deeper and closer to the pumps and thinner, lighter, more irregular and more weathered plastics settling at or near the surface and further from the pumps ${ }^{35,36}$. This behavior indicates an inverse relationship between MPs and MaPs, i.e., samples from the beginning of the site contained large amounts of MaPs but few MPs, whereas few MaPs but numerous MPs would be observed at the opposite end. Therefore, the mass and numerical 
concentrations should follow an inverse trend. However, a covariation between the masses of the MPs and MaPs was observed (SI Figure S5B), suggesting either similar deposition processes or the in situ degradation of MaPs to MPs. In any case, this relation could be extremely practical in large-scale investigations. Indeed, MaPs are easily measurable and could be used as a fingerprint to indicate the probable level of pollution by MPs. A covariation between the mass and number was also observed, suggesting a homogenized pool of plastics at the site (SI Figure S5A).

The plastic distribution in freshly dredged sediments, i.e., just after the filling operation, might also change. Dredged sediments, similar to soils, evolve under the influences of external forcing. Water infiltration is one external force that may transfer particles from the surface to the bottom, and slightly higher concentrations were observed $1 \mathrm{~m}$ below the surface. Waldschläger and Schüttrumpf ${ }^{25}$ suggest that the infiltration of plastics larger than $100 \mu \mathrm{m}$ (i.e., all plastics observed in this study) may occur in soils. Nevertheless, their experimental conditions $(4600 \mathrm{~mL} / \mathrm{min}$ of water flow for 1 hour through a $194 \mathrm{~mm}$ internal diameter column filled with glass spheres) were drastically different from the natural processes that occur in dredged sediments. Bioturbation may also vertically transfer particles. Rillig et $a l .{ }^{27}$ experimentally demonstrated that bioturbation could influence the plastic distribution, but the occurrence of this process in the natural environment remains largely unknown.

\section{Levels of plastic pollution in European watersheds}

To our knowledge, only one study on plastic buried in dredged sediment has been reported $^{14}$. Consequently, our results can be compared more significantly with studies of actual riverbed sediment, but direct comparisons should be made with caution. As previously mentioned, sediment dredging and deposition operations may change the initial riverbed plastic concentrations. 
Likewise, no data are available for MaP concentrations in riverbed sediments in European watersheds. The MP concentrations measured at the two sites varied between $9 \times 10^{-1}$ and $3 \times$ $10^{3}$ items $/ \mathrm{kg}$, corresponding to the lowest range of MP concentrations measured in various

321 European riverbed locations to date (Table S4) ${ }^{1,19,37-39}$. Concentrations within the same order of magnitude should be considered, in a first approximation, as similar. Indeed, sample collection and treatment, especially visual sorting and FTIR validation, potentially create noticeable differences between studies. Horton et al. ${ }^{1}$ found moderate concentrations $\left(3 \times 10^{2}\right.$ items $/ \mathrm{kg}$ ) in the Thames River (United Kingdom; UK), despite their focus on larger MPs (>1 $\mathrm{mm}$ ). In other studies with similar concentrations to those in found in our study, lower percentages of fibers $(<25 \%)$ were observed. On average, fibers accounted for $65 \%$ (site 1 ) and $86 \%$ (site 2) of all the MP items collected in our study. They were also predominant at the bottom of the canals in Amsterdam (Netherlands) ${ }^{40}$ and reached up to $75 \%$ of the MPs in the riverbed sediment of the Ebro River (Spain) ${ }^{41}$. In both studies, the observed concentrations were one order of magnitude higher than ours. The concentrations observed in the Irwell and Mersey catchments (UK; $7 \times 10^{4}$ items $/ \mathrm{kg}$ ), the Roter River (Germany; $5 \times 10^{4}$ items $/ \mathrm{kg}$ ) and the Rhin River (Germany; $10^{5}$ items $/ \mathrm{kg}$ ) were two orders of magnitudes higher, but a negligible amount of fibers was detected $(<10 \%)^{18,34,42}$, and these studies had a lower size limit $(<50 \mu \mathrm{m})$. Note that Frei et al. ${ }^{42}$ and Mani et al. ${ }^{18}$ used a semi-automatic $\mu$ FTIR procedure to analyze very small MPs.

Plastic fibers are also predominant in numerous other environmental settings, such as wastewater, atmospheric fallout and deep-sea sediment ${ }^{43-45}$. Textiles have been pinpointed as a major source of synthetic fibers ${ }^{30}$, but they can also originate from fishing lines and gear $^{46,47}$. Notably, one major pathway for MPs to reach riverbed sediment is effluents from wastewater treatment plants (WWTPs). Indeed, WWTPs receive wastewater from washing machines, which can emit up to 700,000 fibers during a single wash ${ }^{30}$. Even when the 
removal efficiency is high (up to $98 \%$ ) $^{45}$, the treated effluent flowing into rivers still contains massive amounts of MPs. Moreover, synthetic fibers are partly trapped in sewage sludge, representing a supplementary source to agricultural watersheds ${ }^{48}$.

Twenty distinct polymers were observed, but six of them (i.e., PE, PP, PS, PA, PES and PVC) accounted for more than two-thirds of the total. They are among the most produced polymers ${ }^{49}$, and massive amounts of them are also found in other European riverbeds (Table S4). Horton et al. ${ }^{1}$ observed a significant contribution of dyes (62\%) to their polymer pool in the Thames River (UK) and a negligible proportion of low-density polymers (PE, PP and PS $\leq 5 \%$ ). Low-density polymers represent more than half of the polymers detected in the MP and $\mathrm{MaP}$ fragments, films, foams and beads in our study. These results are in the range of observations made in the Tame River $(\mathrm{UK} ; \mathrm{PE}=50 \%)^{39}$ and Irwell and Mersey catchments $(\mathrm{UK} ; 35 \%)^{34}$ but lower than those made in Swiss floodplains $(>88 \%)^{19}$.

This study provides an accurate inventory of the qualities and quantities of plastics trapped in a dredging deposition site and discusses the possible role of external forcing on MaP and MP distributions. These initial promising data open the way for other studies, including those on the redistribution of this contamination in deposited sediments, the associations between plastics and other sedimentary particles, the transfer and degradation of plastics during soil placement, and matrix changes. 


\section{Corresponding Author}

362

363

364

365

366

367

368

369

370

371

372

373

374

* Corresponding author: mel.constant@lilo.org

\section{Author Contributions}

C.A and G.B. conceived the idea for this piece. M.C., C.A., and G.B. designed the research. M.C. and N.B. conducted the data collection and analysis under the supervision of I.D.W. M.C., C.A., I.D.W., D.D. and G.B. wrote the manuscript.

\section{Funding}

This research was supported by the European Fund for Regional Development Interreg.

\section{Acknowledgement}

We acknowledge the European Fund for Regional Development Interreg for funding the post-doc grant of Mel Constant and supported this research through the VALSE project. The Region Hauts de France and the French government are warmly acknowledged through the founding of the CPERs Climibio and ECRIN. We thank LASIRE lab member Myriam Moreau and LGCgE lab members Johanna Caboche, Guillaume Potier, Damien Betrancourt and Dominique Dubois for their helps with the samples preparation, and Vincent Thiery for his advises on the use of the dissecting stereo-microscope. We are also grateful to BRGM members Philippe Bataillard and Samuel Coussy, for coordinated the field campaign (and providing the site history).

\section{Supporting Information}

Method details on the study area, sediment collection, preparation of the samples prior to analysis, contamination protection, FTIR spectroscopy, sediment particle size distribution analysis and data analysis. Main features of the sampled sites (Table S1), mean and range of plastic concentrations (Table S2), results (P-values) of the statistical analysis (Table S3), plastics concentrations within European river sediment (Table S4), images of macroplastics (Figure S1) and microplastic shapes (Figure S2), grain size distribution of sediment samples 
386 (Figure S3), overall FTIR spectroscopy analysis results (Figure S4), and the relationships 387 between plastic concentrations (Figure S5)(PDF).

\section{Abbreviations}

389 MPs: microplastics; MaPs: macroplastics; FTIR: Fourier Transform InfraRed; PE: 390 polyethylene; PP: polypropylene; PS: polystyrene; PVC: polychlorure vinyl; PA: polyamide; 391 PES: polyester; POP: persistent organic pollutants; WWTP: wastewater treatment plant; ATR:

392 Attenuated Total Reflection; DTGS: Deuterated Triglycine Sulfate; MCT: Mercuric 393 Cadmium Telluride; SRH: Scheirer-Ray-Hare 
395 (1) Horton, A. A.; Walton, A.; Spurgeon, D. J.; Lahive, E.; Svendsen, C. Microplastics in Freshwater and Terrestrial Environments: Evaluating the Current Understanding to Identify the Knowledge Gaps and Future Research Priorities. Sci. Total Environ. 2017, 586, 127-141. https://doi.org/10.1016/j.scitotenv.2017.01.190.

(2) Best, J. Anthropogenic Stresses on the World's Big Rivers. Nat. Geosci. 2019, 12 (1), 7-21. https://doi.org/10.1038/s41561-018-0262-x.

(3) Farrell, P.; Nelson, K. Trophic Level Transfer of Microplastic: Mytilus Edulis (L.) to Carcinus Maenas (L.). Environ. Pollut. 2013, 177, 1-3. https://doi.org/10.1016/j.envpol.2013.01.046.

(4) Rochman, C. M.; Tahir, A.; Williams, S. L.; Baxa, D. V.; Lam, R.; Miller, J. T.; Teh, F.-C.; Werorilangi, S.; Teh, S. J. Anthropogenic Debris in Seafood: Plastic Debris and Fibers from Textiles in Fish and Bivalves Sold for Human Consumption. Sci. Rep. 2015, 5 (1), 1-10. https://doi.org/10.1038/srep14340.

(5) Watts, A. J. R.; Lewis, C.; Goodhead, R. M.; Beckett, S. J.; Moger, J.; Tyler, C. R.; Galloway, T. S. Uptake and Retention of Microplastics by the Shore Crab Carcinus Maenas. Environ. Sci. Technol. 2014, 48 (15), 8823-8830. https://doi.org/10.1021/es501090e.

(6) Bakir, A.; Rowland, S. J.; Thompson, R. C. Transport of Persistent Organic Pollutants by Microplastics in Estuarine Conditions. Estuar. Coast. SHELF Sci. 2014, 140, 14-21. https://doi.org/10.1016/j.ecss.2014.01.004.

(7) Turner, A.; Holmes, L. A. Adsorption of Trace Metals by Microplastic Pellets in Fresh Water. Environ. Chem. 2015, 12 (5), 600-610. https://doi.org/10.1071/EN14143.

(8) Teuten, E. L.; Rowland, S. J.; Galloway, T. S.; Thompson, R. C. Potential for Plastics to Transport Hydrophobic Contaminants. Environ. Sci. Technol. 2007, 41 (22), 7759-7764. https://doi.org/10.1021/es071737s.

(9) GESAMP. Sources, Fate and Effects of Microplastics in the Marine Environment: A Global Assessment, IMO/FAO/UNESCO-IOC/UNIDO/WMO/IAEA/UN/UNEP/UNDP Joint Group of Experts on the Scientific Aspects of Marine Environmental Protection).; Rep. Stud. GESAMP; 2015. https://doi.org/10.13140/RG.2.1.3803.7925.

(10) Andrady, A. L. Persistence of Plastic Litter in the Oceans. In Marine Anthropogenic Litter; Bergmann, M., Gutow, L., Klages, M., Eds.; Springer International Publishing, 2015; pp 57-72. https://doi.org/10.1007/978-3-319-16510-3_3.

(11) Rochman, C. M. Microplastics Research-from Sink to Source. Science 2018, 360 (6384), 2829. https://doi.org/10.1126/science.aar7734.

(12) Eerkes-Medrano, D.; Thompson, R. C.; Aldridge, D. C. Microplastics in Freshwater Systems: A Review of the Emerging Threats, Identification of Knowledge Gaps and Prioritisation of Research Needs. Water Res. 2015, 75, 63-82. https://doi.org/10.1016/j.watres.2015.02.012.

(13) Gong, J.; Xie, P. Research Progress in Sources, Analytical Methods, Eco-Environmental Effects, and Control Measures of Microplastics. Chemosphere 2020, 254, 126790. https://doi.org/10.1016/j.chemosphere.2020.126790.

(14) Ji, X.; Ma, Y.; Zeng, G.; Xu, X.; Mei, K.; Wang, Z.; Chen, Z.; Dahlgren, R.; Zhang, M.; Shang, X. Transport and Fate of Microplastics from Riverine Sediment Dredge Piles: Implications for Disposal. J. Hazard. Mater. 2021, 404, 124132. https://doi.org/10.1016/j.jhazmat.2020.124132.

(15) SmageAa. Rapport d'activité 2016, Syndicat Mixte Pour l'aménagement et La Gestion Des Eaux de l'Aa. 2016. https://www.smageaa.fr/le-rapport-dactivite-2016-est-en-ligne/.

(16) CLC. CORINE Land Cover Database Hosted by the French Ministry for the Ecological Transition. 2012. https://www.statistiques.developpement-durable.gouv.fr/corine-land-cover-0.

(17) Claessens, M.; Van Cauwenberghe, L.; Vandegehuchte, M. B.; Janssen, C. R. New Techniques for the Detection of Microplastics in Sediments and Field Collected Organisms. Mar. Pollut. Bull. 2013, 70 (1-2), 227-233. https://doi.org/10.1016/j.marpolbul.2013.03.009. 
(18) Mani, T.; Primpke, S.; Lorenz, C.; Gerdts, G.; Burkhardt-Holm, P. Microplastic Pollution in Benthic Midstream Sediments of the Rhine River. Environ. Sci. Technol. 2019, 53 (10), 60536062. https://doi.org/10.1021/acs.est.9b01363.

(19) Scheurer, M.; Bigalke, M. Microplastics in Swiss Floodplain Soils. Environ. Sci. Technol. 2018, 52 (6), 3591-3598. https://doi.org/10.1021/acs.est.7b06003.

(20) Constant, M.; Kerhervé, P.; Mino-Vercellio-Verollet, M.; Dumontier, M.; Sànchez Vidal, A.; Canals, M.; Heussner, S. Beached Microplastics in the Northwestern Mediterranean Sea. Mar. Pollut. Bull. 2019, 142, 263-273. https://doi.org/10.1016/j.marpolbul.2019.03.032.

(21) Constant, M.; Kerherve, P.; Sola, J.; Sanchez-Vidal, A.; Canals, M.; Heussner, S. Floating Microplastics in the Northwestern Mediterranean Sea: Temporal and Spatial Heterogeneities. In Proceedings of the International Conference on Microplastic Pollution in the Mediterranean Sea; Cocca, M., Di Pace, E., Errico, M. E., Gentile, G., Montarsolo, A., Mossotti, R., Eds.; Springer Water; Springer International Publishing: Cham, 2018; pp 9-15. https://doi.org/10.1007/978-3-319-71279-6_2.

(22) Constant, M.; Kerhervé, P.; Heussner, S. Source, Transfer, and Fate of Microplastics in the Northwestern Mediterranean Sea: A Holistic Approach. In Fate and Impact of Microplastics in Marine Ecosystems; Baztan, J., Jorgensen, B., Pahl, S., Thompson, R. C., Vanderlinden, J.-P., Eds.; Elsevier, 2017; pp 115-116. https://doi.org/10.1016/B978-0-12-812271-6.00111-3.

(23) Accinelli, C.; Abbas, H. K.; Shier, W. T.; Vicari, A.; Little, N. S.; Aloise, M. R.; Giacomini, S. Degradation of Microplastic Seed Film-Coating Fragments in Soil. Chemosphere 2019, 226, 645-650. https://doi.org/10.1016/j.chemosphere.2019.03.161.

(24) Eubeler, J. P.; Bernhard, M.; Knepper, T. P. Environmental Biodegradation of Synthetic Polymers II. Biodegradation of Different Polymer Groups. TrAC Trends Anal. Chem. 2010, 29 (1), 84-100. https://doi.org/10.1016/j.trac.2009.09.005.

(25) Waldschläger, K.; Schüttrumpf, H. Infiltration Behavior of Microplastic Particles with Different Densities, Sizes, and Shapes-From Glass Spheres to Natural Sediments. Environ. Sci. Technol. 2020, 54 (15), 9366-9373. https://doi.org/10.1021/acs.est.0c01722.

(26) O'Connor, D.; Pan, S.; Shen, Z.; Song, Y.; Jin, Y.; Wu, W.-M.; Hou, D. Microplastics Undergo Accelerated Vertical Migration in Sand Soil Due to Small Size and Wet-Dry Cycles. Environ. Pollut. Barking Essex 1987 2019, 249, 527-534. https://doi.org/10.1016/j.envpol.2019.03.092.

(27) Rillig, M. C.; Ziersch, L.; Hempel, S. Microplastic Transport in Soil by Earthworms. Sci. Rep. 2017, 7, 1362. https://doi.org/10.1038/s41598-017-01594-7.

(28) Geyer, R.; Jambeck, J. R.; Law, K. L. Production, Use, and Fate of All Plastics Ever Made. Sci. Adv. 2017, 3 (7), e1700782.

(29) Frère, L.; Paul-Pont, I.; Rinnert, E.; Petton, S.; Jaffré, J.; Bihannic, I.; Soudant, P.; Lambert, C.; Huvet, A. Influence of Environmental and Anthropogenic Factors on the Composition, Concentration and Spatial Distribution of Microplastics: A Case Study of the Bay of Brest (Brittany, France). Environ. Pollut. 2017, 225, 211-222. https://doi.org/10.1016/j.envpol.2017.03.023.

(30) Napper, I. E.; Thompson, R. C. Release of Synthetic Microplastic Plastic Fibres from Domestic Washing Machines: Effects of Fabric Type and Washing Conditions. Mar. Pollut. Bull. 2016, 112 (1-2), 39-45. https://doi.org/10.1016/j.marpolbul.2016.09.025.

(31) González Fernández, D.; Hanke, G.; Kideys, A.; Alicia, N.; Sanchez-Vidal, A.; Bruge, A.; Bayram, öztürk; Palma, C.; Santinelli, C.; Daan, D.; Damia, B.; Elias, D.; Rojo-Nieto, E.; Fernando, F.; Bessa, F.; Suaria, G.; Siedlewicz, G.; Castro-Jiménez, J.; Joana, G.; Yuri, G. Floating Macro Litter in European Rivers-Top Items; 2018. https://doi.org/10.2760/316058.

(32) Cerema. Rétrospective Des Dragages Fluviaux En France - Période 2006-2010. Ed. Cerema 2018. https://www.cerema.fr/fr/centre-ressources/boutique/retrospective-dragages-fluviauxfrance.

(33) Boots, B.; Russell, C. W.; Green, D. S. Effects of Microplastics in Soil Ecosystems: Above and Below Ground. Environ. Sci. Technol. 2019, 53 (19), 11496-11506. https://doi.org/10.1021/acs.est.9b03304. 
(34) Hurley, R.; Woodward, J.; Rothwell, J. J. Microplastic Contamination of River Beds Significantly Reduced by Catchment-Wide Flooding. Nat. Geosci. 2018, 11 (4), 251. https://doi.org/10.1038/s41561-018-0080-1.

(35) Waldschläger, K.; Schüttrumpf, H. Effects of Particle Properties on the Settling and Rise Velocities of Microplastics in Freshwater under Laboratory Conditions. Environ. Sci. Technol. 2019, 53 (4), 1958-1966. https://doi.org/10.1021/acs.est.8b06794.

(36) Waldschläger, K.; Born, M.; Cowger, W.; Gray, A.; Schüttrumpf, H. Settling and Rising Velocities of Environmentally Weathered Micro- and Macroplastic Particles. Environ. Res. 2020, 110192. https://doi.org/10.1016/j.envres.2020.110192.

(37) Guerranti, C.; Cannas, S.; Scopetani, C.; Fastelli, P.; Cincinelli, A.; Renzi, M. Plastic Litter in Aquatic Environments of Maremma Regional Park (Tyrrhenian Sea, Italy): Contribution by the Ombrone River and Levels in Marine Sediments. Mar. Pollut. Bull. 2017, 117 (1-2), 366-370. https://doi.org/10.1016/j.marpolbul.2017.02.021.

(38) Rodrigues, M. O.; Abrantes, N.; Goncalves, F. J. M.; Nogueira, H.; Marques, J. C.; Goncalves, A. M. M. Spatial and Temporal Distribution of Microplastics in Water and Sediments of a Freshwater System (Antua River, Portugal). Sci. Total Environ. 2018, 633, 1549-1559. https://doi.org/10.1016/j.scitotenv.2018.03.233.

(39) Tibbetts, J.; Krause, S.; Lynch, I.; Sambrook Smith, G. Abundance, Distribution, and Drivers of Microplastic Contamination in Urban River Environments. Water 2018, 10 (11), 1597. https://doi.org/10.3390/w10111597.

(40) Leslie, H. A.; Brandsma, S. H.; van Velzen, M. J. M.; Vethaak, A. D. Microplastics En Route: Field Measurements in the Dutch River Delta and Amsterdam Canals, Wastewater Treatment Plants, North Sea Sediments and Biota. Environ. Int. 2017, 101, 133-142. https://doi.org/10.1016/j.envint.2017.01.018.

(41) Simon-Sánchez, L.; Grelaud, M.; Garcia-Orellana, J.; Ziveri, P. River Deltas as Hotspots of Microplastic Accumulation: The Case Study of the Ebro River (NW Mediterranean). Sci. Total Environ. 2019, 687, 1186-1196. https://doi.org/10.1016/j.scitotenv.2019.06.168.

(42) Frei, S.; Piehl, S.; Gilfedder, B. S.; Löder, M. G. J.; Krutzke, J.; Wilhelm, L.; Laforsch, C. Occurence of Microplastics in the Hyporheic Zone of Rivers. Sci. Rep. 2019, 9 (1), 15256. https://doi.org/10.1038/s41598-019-51741-5.

(43) Dris, R.; Gasperi, J.; Saad, M.; Mirande, C.; Tassin, B. Synthetic Fibers in Atmospheric Fallout: A Source of Microplastics in the Environment? Mar. Pollut. Bull. 2016, 104 (1), 290-293. https://doi.org/10.1016/j.marpolbul.2016.01.006.

(44) Sanchez-Vidal, A.; Thompson, R. C.; Canals, M.; de Haan, W. P. The Imprint of Microfibres in Southern European Deep Seas. PLOS ONE 2018, 13 (11), e0207033. https://doi.org/10.1371/journal.pone.0207033.

(45) Murphy, F.; Ewins, C.; Carbonnier, F.; Quinn, B. Wastewater Treatment Works (WwTW) as a Source of Microplastics in the Aquatic Environment. Environ. Sci. Technol. 2016, 50 (11), 5800-5808. https://doi.org/10.1021/acs.est.5b05416.

(46) Claessens, M.; Meester, S. D.; Landuyt, L. V.; Clerck, K. D.; Janssen, C. R. Occurrence and Distribution of Microplastics in Marine Sediments along the Belgian Coast. Mar. Pollut. Bull. 2011, 62 (10), 2199-2204. https://doi.org/10.1016/j.marpolbul.2011.06.030.

(47) Lots, F. A. E.; Behrens, P.; Vijver, M. G.; Horton, A. A.; Bosker, T. A Large-Scale Investigation of Microplastic Contamination: Abundance and Characteristics of Microplastics in European Beach Sediment. Mar. Pollut. Bull. 2017, 123 (1), 219-226. https://doi.org/10.1016/j.marpolbul.2017.08.057.

(48) Zubris, K. A. V.; Richards, B. K. Synthetic Fibers as an Indicator of Land Application of Sludge. Environ. Pollut. 2005, 138 (2), 201-211. https://doi.org/10.1016/j.envpol.2005.04.013.

(49) Plastics Europe. Plastics-The Facts - An Analysis of European Plastics Production, Demand and Waste Data. 2019. 
547 Abstract Graphic: For Table of Contents Only

548

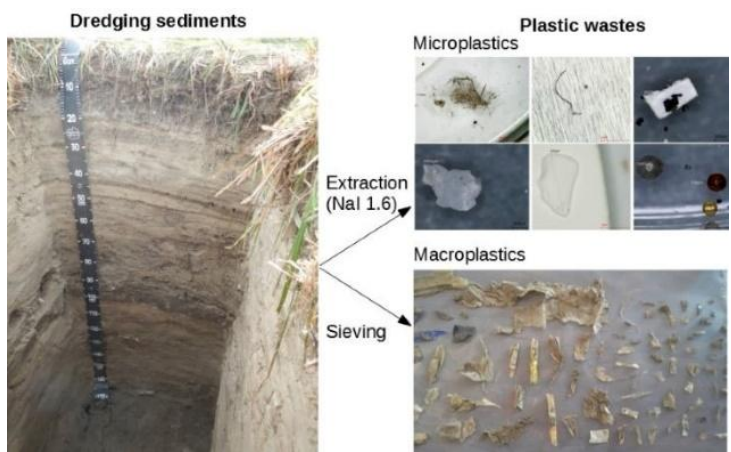

